\title{
The effect of surgeon volume on procedure selection in non-small cell lung cancer surgeries
}

\author{
Ivana Camposilvan, BHSc, ${ }^{\mathrm{a}}$ Noori Akhtar-Danesh, $\mathrm{PhD},{ }^{\mathrm{b}}$ Laura Schneider, BSc, ${ }^{\mathrm{a}}$ and \\ Christian J. Finley, MD, MPH
}

\begin{abstract}
Objectives: Procedure selection by the surgeon can greatly affect patients' operative and long-term survival. This selection potentially reflects comfort with technically challenging surgeries. This study aims to examine surgeon choices for non-small cell lung cancer and whether surgeon volume predicts the type of procedure chosen, controlling for patient demographics, comorbidity, year of surgery, and institutional factors.
\end{abstract}

Methods: Data were abstracted from an Ontario population-based linked database from 2004 to 2011. Patient demographics, comorbidities, year of surgery, and institutional and surgical factors were evaluated. Three-level, randomeffect, multilevel regression analyses were performed to examine factors influencing operative selection.

Results: Over the interval, 8070 patients (50.4\% were male) underwent surgical resection, including pneumonectomy $(\mathrm{n}=842)$, lobectomy $(\mathrm{n}=6212)$, and wedge resection $(n=1002)$. Resections were performed by 124 unique physicians in 45 institutions. The proportion of patients undergoing pneumonectomy decreased from $14.8 \%$ in 2004 to $7.6 \%$ in 2011 . Multilevel regression analysis showed physician volume, age, year of procedure, gender, and comorbidities were predictive of performing a pneumonectomy. By adjusting for these variables, the results indicated that for each 10-unit increase in physician volume, the relative risk of performing a pneumonectomy decreased by $9.1 \%$ (95\% confidence interval, 8.2-10.0, $P=.04$ ).

Conclusions: Although patient and temporal factors influence the type of resection a patient receives for non-small cell lung cancer, surgeon volume also is a strong predictor. This study may be limited by minimal stage data, but the suggestion that a surgeon's total procedural volume for non-small cell lung cancer significantly influences procedure selection has implications on how we deliver care to this patient population. (J Thorac Cardiovasc Surg 2015;150:507-13)

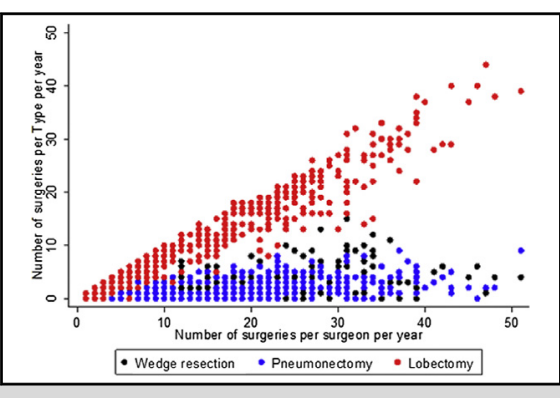

Observed relationship between surgeon volume and procedure type.

\section{Central Message}

Surgeon volume is a predictor of procedure selection along with within-patient factors and has implications on the delivery of care.

\section{Perspective}

The type of resection selected significantly affects a patient's operative and long-term survival. If a surgeon with high surgical volumes is less likely to perform higher-risk pneumonectomy procedures than one with lower volumes, this may translate to a significant reduction in adverse events. Surgeon volume should be considered an important component in how care is delivered in this population.

See Editorial page 458.

\footnotetext{
From the a Department of Surgery, McMaster University, St Joseph's Healthcare Hamilton, Hamilton, Ontario; and ${ }^{\mathrm{b}}$ School of Nursing, McMaster University, Hamilton, Ontario.

McMaster University, Division of Thoracic Surgery. This study was supported through provision of data by the Institute for Clinical Evaluative Sciences (ICES) and Cancer Care Ontario and through funding support to ICES from an annual grant by the Ministry of Health and Long-Term Care and the Ontario Institute for Cancer Research. The opinions, results, and conclusions reported in this article are those of the authors and are independent from the funding sources. No endorsement by ICES, Cancer Care Ontario, Ontario Institute for Cancer Research, or the Government of Ontario is intended or should be inferred.

Read at the 95th Annual Meeting of The American Association for Thoracic Surgery, Seattle, Washington, April 25-29, 2015.

Received for publication Nov 26, 2014; revisions received April 1, 2015; accepted for publication April 7, 2015; available ahead of print July 26, 2015.

Address for reprints: Christian J. Finley, MD, MPH, St Joseph's Healthcare Hamilton, 50 Charlton Avenue East, Juravinski Tower T-2105B, Hamilton, ON L8N 4A6, Canada (E-mail: finleyc@mcmaster.ca).

$0022-5223 / \$ 36.00$

Copyright (c) 2015 by The American Association for Thoracic Surgery

http://dx.doi.org/10.1016/j.jtcvs.2015.04.060
}

Lung cancer represents a large burden of disease affecting health care systems worldwide. ${ }^{1-3}$ In Canada, it is the second most common cancer in both male and female individuals, and the fourth most prevalent cancer overall. ${ }^{4}$ It is estimated that 25,500 new cases of lung cancer were diagnosed in $2013 .{ }^{4}$ Despite the significant decrease in the lung cancer mortality rate over the past 20 years, it remains the leading cause of cancer-related death in Canada, accounting for the deaths of 20,200 Canadians in $2013 .{ }^{4}$

Surgical resection is associated with optimal outcomes for early-stage lung cancer. ${ }^{3-8}$ Approximately $20 \%$ to $25 \%$ of patients undergo resection because it provides the best longterm survival for those with non-small cell lung cancer (NSCLC). ${ }^{9-11}$ Surgically resectable patients undergo anatomic resections, pneumonectomy and lobectomy, or 


\section{Abbreviations and Acronyms \\ CCI = Charlson Comorbidity Index \\ NSCLC $=$ non-small cell lung cancer}

sublobar resections, including segmentectomy and wedge resection..$^{2-4,12}$ Lobectomy is noted as the most common and recommended resection choice for patients with early-stage NSCLC. ${ }^{1-5}$ Lobectomy is ideal because of its parenchymasparing technique and a decreased rate of cancer recurrence compared with lesser resections, ${ }^{1-3,13}$ although sublobar resections also can result in reasonable outcomes in appropriately selected patients. ${ }^{1,3,11,14}$ Pneumonectomy is less desirable with a significantly higher morbidity and mortality rate, reported to be approximately $10 \%$, whereas lobectomy and subanatomic resections have reported rates of $4 \%$ and less than $4 \%$, respectively. ${ }^{15-18}$ This indicates that pneumonectomy cases carry a 3 -fold greater mortality than the other resection types. A pneumonectomy is often avoidable with the use of advanced techniques, although this procedure is occasionally necessary because of tumor location. $^{1,2}$

Procedure selection by the surgeon has one of the greatest effects on patients' operative and long-term survival. Well-established pathologic and physiologic factors influence a surgeon's choice of surgery, including tumor biology and location, extent of disease (stage), and patientspecific factors, such as age, pulmonary function, and comorbidity. ${ }^{1-3,12,14}$ Only over the past decade have surgeonspecific factors, such as experience, training, and volume, been identified and examined as other important determinants of outcomes in patients with lung cancer. ${ }^{3,19-21}$ Resections performed by dedicated thoracic surgeons are reported to be advantageous, resulting in lower mortality and improved survival. ${ }^{1,3,19-21}$ Likewise, hospital volume is associated with improved surgical outcome after lung cancer resection. ${ }^{18,19}$

It is intuitive that surgeon-specific factors, such as experience, influence a surgeon's procedure selection. It is hypothesized that choice of surgery may reflect the surgeon's comfort level with technically challenging procedures. That is, a surgeon with less expertise may be more inclined to perform a pneumonectomy or sublobar resections, which can be less challenging than a guideline-recommended standard or sleeve lobectomy. This potential relationship has not been addressed in the current literature. Therefore, the aim of this study is to examine the choice of procedure that surgeons make for NSCLC and whether a surgeon's volume is predictive of the type of procedure, controlling for patient demographics, comorbidity, year of surgery, and institutional factors.

\section{MATERIALS AND METHODS}

The dataset was constructed from the population-based linked databases accessed via the Institute for Clinical Evaluate Sciences. These databases included data from the Ontario Cancer Registry, Ontario Health Insurance Plan claims, Canadian Institutes for Health Information Discharge Abstract Database, and the National Ambulatory Care Reporting Service database. All patients in Ontario who underwent any pulmonary resection for primary NSCLC during 2004 to 2011 were included. The Canadian enhancement of the International Classification of Diseases 10th revision was used to describe diagnosis and morphology. Inclusion of code C34.XX, referring to neoplasm located within the lung, with the attendant morphology codes for primary squamous cell carcinoma not otherwise specified, primary adenocarcinoma, primary bronchioalveolar adenocarcinoma, and primary alveolar adenocarcinoma, ensured that all types of patients with NSCLC were included. All surgeons are trained as general thoracic surgeons, who have completed a 2-year residency after qualifying as a general or cardiac surgeon, as per Ontario thoracic surgery practice standards.

To reduce the confounding effect of cancer reoccurrence, all Z85 codes, indicating a personal history of other malignant neoplasms, were excluded. Synchronous tumors were excluded because of the varied nature of their occurrence. Secondary or extended resections were not analyzed. Only pneumonectomy, lobectomy, and wedge resection procedures were examined. Both thoracotomy and thoracoscopic procedures were included in the analysis. Laterality of surgery, physical performance test results (eg, physical fitness testing, maximum value of oxygen, and exercise tolerance tests), Eastern Cooperative Oncology Group score, histology of tumor, and causes of mortality were not analyzed because these variables were not available in the dataset.

De-identified information on gender, age, year of procedure, income quintile, location of residence (rural vs urban), institution volume (total number of surgeries performed per institution per year), surgeon volume (total number of surgeries performed per surgeon per year), length of stay, in-hospital mortality, and postdischarge mortality was collected. Comorbidities were recorded using the Charlson Comorbidity Index (CCI) both as individual conditions and as an aggregate index score. To adjust for risk factors, the CCI was calculated using prehospitalization Canadian enhancement of the International Classification of Diseases 10th revision codes, following a previously validated method. ${ }^{22-24}$ The study was approved by the Hamilton Integrated Research Ethics Board with a waiver of patient consent.

Patient characteristics were summarized, and descriptive and graphic assessments of outcome trends over time were performed. Age data were available only as grouped intervals. Thus, to estimate average age, the products of the midpoint of each class interval and the frequency for that interval were summed and divided by the total of all frequencies. The lowest and highest intervals were excluded from this calculation because a midpoint could not be determined for the "low to 35" or "91-high" intervals.

The 90-day mortality for each procedure was calculated. Multilevel logistic regression analyses were performed to examine factors that influence a surgeon's choice of surgery. A 3-level random effects model was used to control for the cluster effect of physician nested within institution. Patient age, gender, year of surgery, location of residence (urban, rural), income quintile, and risk factors as determined by the CCI were adjusted for in the analyses. Variables with a significant effect on each outcome variable were reported.

Because of limited availability, stage data could not be included as a predictor variable in the regression model. However, accurate stage data were available for the last 2 years of study, 2010 and 2011. These were added to the multilevel regression model to examine trends that could be attributed to stage of disease. Because of small sample sizes, stage I and substages IA and IB were grouped into a single class variable with no difference to final outcomes, and substages of stage II, III, and IV were grouped in the same manner. Stages 0, X, NS, NA, or otherwise unknown were excluded for clarity of analysis. Stage I was used as the reference variable.

By using the available stage data from 2010 and 2011, the relationship between stage and surgeon volume was also analyzed. Low-, medium-, and high-volume surgeons were distinguished by dividing the variable into tertiles. STATA/SE software version 12.1 (StataCorp LP, College Station, Tex) was used to complete the statistical analyses. 
TABLE 1. Patient characteristics

\begin{tabular}{|c|c|}
\hline Variable & No. $(\%)$ \\
\hline Patient total & 8070 \\
\hline Gender, male & $4070(50.4 \%)$ \\
\hline Age, mean (y) & 67 \\
\hline low, 35 & $17(0.2)$ \\
\hline $36-40$ & $29(0.4)$ \\
\hline $41-45$ & $121(1.5)$ \\
\hline $46-50$ & 307 (3.8) \\
\hline $51-55$ & $574(7.1)$ \\
\hline $56-60$ & 918 (11.4) \\
\hline $61-65$ & 1325 (16.4) \\
\hline $66-70$ & $1572(19.5)$ \\
\hline $71-75$ & $1560(19.3)$ \\
\hline $76-80$ & $1120(13.9)$ \\
\hline $81-85$ & $483(6.0)$ \\
\hline $86-90$ & $42(0.5)$ \\
\hline 90-high & $2(0.0)$ \\
\hline \multicolumn{2}{|l|}{ Income quintile* } \\
\hline 1 & $1734(21.5)$ \\
\hline 2 & 1734 (21.5) \\
\hline 3 & 1589 (19.7) \\
\hline 4 & 1564 (19.4) \\
\hline 5 & $1415(17.5)$ \\
\hline \multicolumn{2}{|l|}{ Residence $\dagger$} \\
\hline Rural & $6895(85.4)$ \\
\hline Urban & $1164(14.4)$ \\
\hline \multicolumn{2}{|l|}{ Year of surgery } \\
\hline 2004 & $868(10.8)$ \\
\hline 2005 & $979(12.1)$ \\
\hline 2006 & 1005 (12.5) \\
\hline 2007 & 1079 (13.4) \\
\hline 2008 & $1010(12.5)$ \\
\hline 2009 & $1075(13.3)$ \\
\hline 2010 & $1029(12.8)$ \\
\hline 2011 & 1025 (12.7) \\
\hline \multicolumn{2}{|l|}{$\mathrm{CCI} \ddagger$} \\
\hline Median, range & $2,0-14$ \\
\hline
\end{tabular}

\section{RESULTS}

The study interval from 2004 to 2011 included 8070 patients who underwent surgical resection for NSCLC, of whom 4070 $(50.4 \%)$ were male. The estimated average age was 67 years. Overall patient characteristics are summarized in Table 1.

Resections were performed by 124 unique physicians and 45 institutions, among which 842 patients $(10.4 \%)$ underwent pneumonectomy, 6212 patients $(77.0 \%)$ underwent lobectomy, and 1002 patients $(12.4 \%)$ underwent wedge resection. The proportion of patients undergoing pneumonectomy and wedge resection decreased over time from $14.8 \%$ to $7.6 \%$ and $12.1 \%$ to $10.7 \%$ from 2004 to 2011 , respectively. Those undergoing lobectomy increased from $73.7 \%$ in 2004 to $79 \%$ in 2011 . Assessment of mortality revealed that 90 -day mortality was $12.6 \%, 3.9 \%$, and $5.7 \%$ for pneumonectomy, lobectomy, and wedge resection, respectively. Figure 1 demonstrates the variable mortality trend for the 3 resection types over the study period.

The odds ratios based on the regression models for pneumonectomy, lobectomy, and wedge resection are shown in Table 2. This analysis revealed that physician volume, age, year of procedure, gender, and CCI were all predictive of selecting pneumonectomy as the choice of surgery. After adjusting for all other variables, the results indicated that for each additional 10-unit increase in physician volume, the risk of performing a pneumonectomy decreases by $9.1 \%$ (95\% confidence interval, 8.2-10.0; $P=.04$ ).

Figure 2 shows a graphic representation of the relationship between surgeon volume and procedure selection. As surgeon volume increased, the number of lobectomy procedures performed increased, whereas the number of pneumonectomy and wedge resections performed relatively decreased.

The analysis including stage data for 2010 and 2011 found no association between stage of disease and surgeon volume. That is, there was no significant difference in stage distribution among low-, medium-, and high-volume surgeons. The distribution of stage among the 3 groups is shown in Figure 3.

\section{DISCUSSION}

The way providers deliver care is as important as identifying the ideal clinical management of their patients. Mortality after lung resection is strongly related to postoperative complications, underlining the importance of careful procedure selection to optimize patient outcomes. ${ }^{25}$ Available guidelines provide recommendations for optimal lung cancer treatment selection. First and foremost, accurate staging and risk assessment of patients are vital to treatment decision. ${ }^{2}$ However, if ideal management is not carried out, it is evident that patients will have suboptimal outcomes.

When considering potential confounders, it is important to consider the concurrent advent of diagnostic assessment programs that are aimed at better coordinating the diagnosis and initiation of treatment for patients with suspected lung cancer. As such, it may be possible that tumors are detected at an earlier stage and are then more amenable to smaller or thoracoscopic resections. These programs were initiated in Ontario (www.cancercare.on.ca) starting in the latter half of the decade and have been widely implemented. By looking at the surgical volumes temporally, the distribution of resection types does not change. This indicates that these programs are not confounding the conclusions made in this analysis on a provincial basis, although it is important to note that there may be variance at a local level because of a multitude of reasons. The distribution of resection type also was not affected by the urban/rural location of the patient, indicating that patients in a rural location were not patently of a later stage or requiring a more complex procedure.

Surgical quality indicators have become increasingly important in elucidating the short- and long-term impacts of a surgical procedure. ${ }^{25}$ Among these, surgeon specialty 


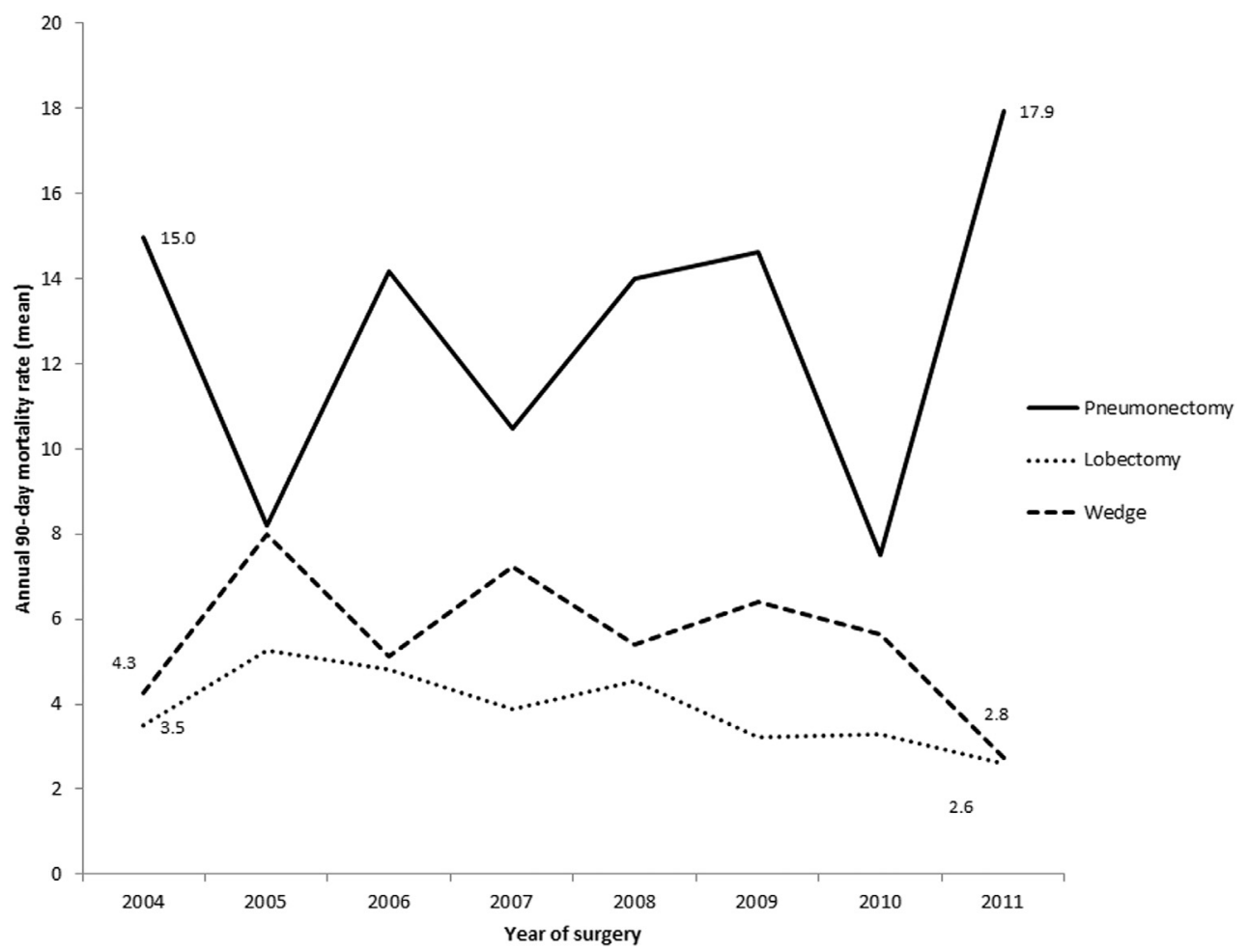

FIGURE 1. Distribution of mean 90-day mortality rates for each resection type per year.

and training have been identified as notable determinants of outcome for patients receiving lung cancer resection. ${ }^{3,19-21}$ Mortality after pulmonary resection is significantly lower when performed by a thoracic surgeon when compared with a general surgeon. ${ }^{25}$ Likewise, superior outcomes have been reported in hospitals with a thoracic surgery residency program. ${ }^{25}$

The effect of volume on outcome also has been given considerable attention in the recent literature. Generally, high volume at both hospital and physician levels has been

TABLE 2. Odds ratios based on the mixed-effects logistic regression model for different types of surgery

\begin{tabular}{lrrr}
\hline \multicolumn{1}{c}{ Variable } & OR & $\boldsymbol{P}$ value & 95\% CI \\
\hline Pneumonectomy & & & \\
Physician volume & 0.91 & .040 & $0.83-1.00$ \\
Age & 0.85 & $<.001$ & $0.82-0.88$ \\
Year & 0.88 & $<.001$ & $0.85-0.92$ \\
Gender & 1.69 & $<.001$ & $1.44-1.97$ \\
CCI & 1.25 & $<.001$ & $1.21-1.30$ \\
Lobectomy & & & \\
Physician Volume & 1.09 & .012 & $1.02-1.17$ \\
Age & 1.03 & .032 & $1.00-1.06$ \\
Gender & 0.84 & .002 & $0.75-0.94$ \\
CCI & 0.87 & $<.001$ & $0.85-0.90$ \\
Wedge resection & & & \\
Physician volume & 0.96 & .348 & $0.87-1.05$ \\
Gender & 0.88 & .077 & $0.76-1.01$ \\
CCI & 1.05 & .008 & $1.01-1.09$ \\
\hline OR, Odi
\end{tabular}

$O R$, Odds ratio; $C I$, confidence interval; $C C I$, Charlson Comorbidity Index. associated with better outcomes across a range of procedures and conditions. ${ }^{26}$ Hospital volume is well documented as being associated with improved surgical outcome after lung cancer surgery. ${ }^{18,19,27}$ Multiple studies have reported that greater physician volume results in significantly improved operative mortality and survival after lung cancer resection. ${ }^{28}$

Of note, a study by Birkmeyer and colleagues ${ }^{29}$ reported that the association between hospital volume and operative mortality seems to be largely mediated by surgeon volume for many procedures. This study suggests that a patient may improve his/her chance of survival substantially, even

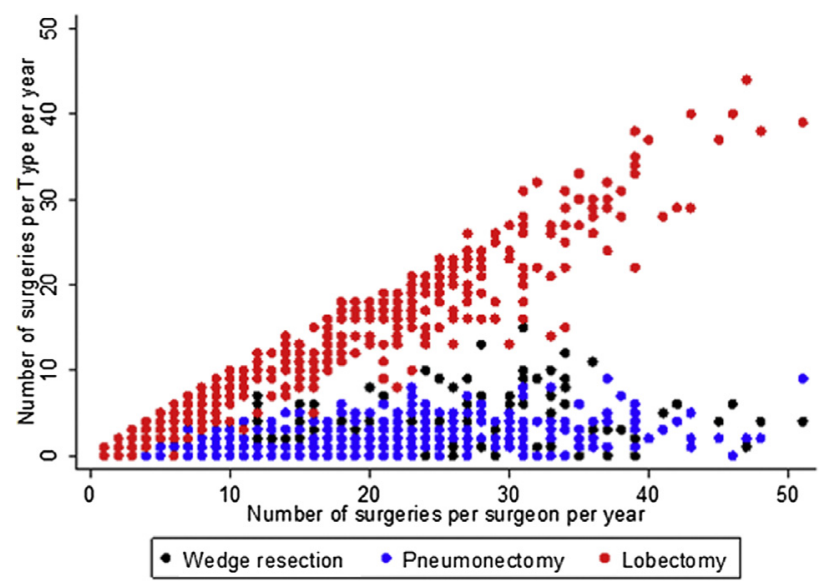

FIGURE 2. Observed relationship between surgeon volume and procedure type. 


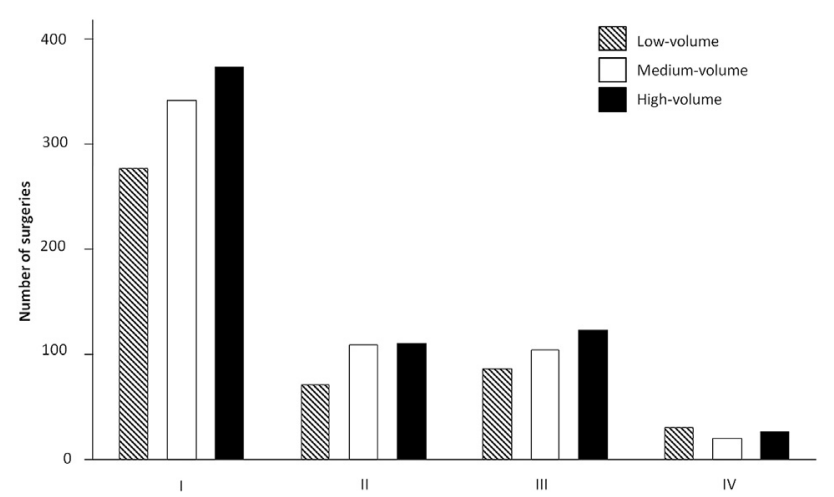

FIGURE 3. Distribution of stage among low-, medium-, and high-volume surgeons.

at high-volume institutions, by selecting surgeons who perform operations more frequently. ${ }^{29}$ Because of the nature of the 3-level random effects regression model, institution volume was not analyzed as a variable. However, surgeon volume was found to be the strongest significant factor predicting pneumonectomy resections. On this basis, the authors suspect that even within moderate-volume institutions, a concentration of provider experience may be beneficial.

There is currently paucity within the literature of studies investigating how surgeons make treatment choices. As mentioned, many factors may influence a surgeon's decision, including their training, the types of cases they encounter (case-mix), and their personal past experience. It was hypothesized that physician expertise and associated comfort level with technically challenging procedures are reflected in their choice of surgery. By using volume of cases per surgeon per year as a surrogate for experience, this study demonstrates a strong influence of experience on a surgeon's procedure selection. Specifically, increased experience decreased the likelihood that the surgeon would perform a pneumonectomy. This result was significant, controlling for patient demographics, comorbidity, year of surgery, and institutional factors. This is meaningful because pneumonectomy is known to have the highest mortality rate of lung cancer resection, found in this study to be $12.6 \%$, demonstrating a potentially large impact on patient survival.

\section{Study Limitations}

As with any secondary analysis of administrative data, this study has several limitations. Although the CCI is well validated for population-based studies, not all comorbid factors known to increase the risk of pulmonary resection are included in this index. ${ }^{22,23,30-33}$ In addition, although the CCI accounts for malignancy, our databases did not have accurate staging for the entire studied time period, limiting our ability to control for those with more advanced disease. One may also argue that differences in case-mix and processes of care between high- and low-volume providers may in part explain the relationship between volume and outcome. ${ }^{26}$ In particular, a common point of contention is that higher-volume surgeons are faced with a greater number of more complex cases. Although stage could not be controlled for in the model because of inadequate stage data for the study duration, complete stage data were available from 2010 and 2011. Analysis of this data showed that low, medium-, and high-volume surgeons encounter a similar case-mix in terms of stage because no significant difference was found between the groups. Also, it is important to note that the retrospectively reviewed nature of the dataset means that we cannot judge whether pneumonectomy procedures were genuinely warranted or whether the rate of occurrence was indeed a result of lower surgeon expertise in smaller centers. This study simply identifies the possible correlation between lower-volume surgeons, who may then have lesser experience because of less time in the operating room, and a higher rate of typically undesirable pneumonectomy cases.

\section{CONCLUSIONS}

Although patient and temporal factors influence the type of resection a patient receives for NSCLC, surgeon volume was found to have a strong association with procedure selection. This is valuable because procedure selection can significantly affect a patient's operative and long-term survival. Despite the limitations, this strong suggestion has implications for how we deliver care to this patient population and warrants additional studies to further examine this relationship.

\section{Conflict of Interest Statement}

Authors have nothing to disclose with regard to commercial support.

You can watch a Webcast of this AATS meeting presentation by going to: http://webcast.aats.org/2015/Video/ Tuesday/04-28-15_6C_1615_Finley.mp4.

\section{References}

1. National Comprehensive Cancer Network. NCCN Clinical Practice Guidelines in Oncology (NCCN Guidelines $\left.{ }^{\circledR}\right)$ : Non Small Cell Lung Cancer. Version 3.2012. Available at: http://www.nccn.org/professionals/physician_gls/f_ guidelines.asp. Accessed August 1, 2013.

2. Vansteenkiste J, De Ruysscher D, Eberhardt WE, Lim E, Senan S, Felip E, et al; ESMO Guidelines Working Group. Early and locally advanced nonsmall-cell lung cancer (NSCLC): ESMO Clinical Practice Guidelines for diagnosis, treatment and follow-up. Ann Oncol. 2013;24 Suppl 6:vi89-98.

3. Baltayiannis N, Chandrinos M, Anagnostopoulos D, Zarogoulidis P, Tsakiridis K, Mpakas A, et al. Lung cancer surgery: an up to date. J Thorac Dis. 2013;5:S425-39.

4. Canadian Cancer Society's Advisory Committee on Cancer Statistics. Canadian Cancer Statistics 2013. Toronto, ON: Canadian Cancer Society; 2013.

5. Howington JA, Blum MG, Chang AC, Balekian AA, Murthy SC. Treatment of stage I and II non-small cell lung cancer: diagnosis and management of lung cancer, 3rd ed: American College of Chest Physicians evidence-based clinical practice guidelines. Chest. 2013;143:e278S-313S.

6. Deslauriers J, Grégoire J. Surgical therapy of early non-small cell lung cancer. Chest. 2000;117:104S-9S.

7. Wright G, Manser RL, Byrnes G, Hart D, Campbell DA. Surgery for non-small cell lung cancer: systematic review and meta-analysis of randomised controlled trials. Thorax. 2006;61:597-603.

8. Manser R, Wright G, Hart D, Byrnes G, Campbell D, Wainer Z, et al. Surgery for local and locally advanced non-small cell lung cancer (review). Cochrane Data base Syst Rev. 2005;CD004699. 
9. Cancer Quality Council of Ontario. Lung and Bronchus Cancers. Available at: http://www.csqi.on.ca/cms/one.aspx?portalId=289784\&pageId=295935. Accessed November 12, 2014.

10. Darling G, Nenshi R, Schultz SE, Gunraj N, Wilton AS, Simunovic M, et al. Surgery for lung cancer. In: Urbach DR, Simunovic M, Schultz SE, eds. Cancer Surgery in Ontario: ICES Atlas. Toronto: Institute for Clinical Evaluative Sciences; 2008:97-126.

11. Damhuis RA, Schütte PR. Resection rates and postoperative mortality in 7,899 patients with lung cancer. Eur Respir J. 1996;9:7-10.

12. Little AG, Rusch VW, Bonner JA, Gaspar LE, Green MR, Webb WR, et al. Patterns of surgical care of lung cancer patients. Ann Thorac Surg. 2005;80: 2051-6.

13. Billmeier SE, Ayanian JZ, Zaslavsky AM, Nerenz DR, Jaklitsch MT, Rogers SO. Predictors and outcomes of limited resection for early-stage non-small cell lung cancer. J Natl Cancer Inst. 2011;103:1621-9.

14. Sugarbaker DJ. Lung cancer. 6: The case for limited surgical resection in nonsmall cell lung cancer. Thorax. 2003;58:639-41.

15. Ginsberg RJ, Hill LD, Eagan RT, Thomas P, Mountain CF, Deslauriers J, et al. Modern thirty-day operative mortality for surgical resections in lung cancer. $J$ Thorac Cardiovasc Surg. 1983;86:654-8.

16. Romano PS, Mark DH. Patient and hospital characteristics related to in-hospital mortality after lung cancer resection. Chest. 1992;101:1332-7.

17. Harpole DH Jr, DeCamp MM Jr, Daley J, Hur K, Oprian CA, Henderson WG, et al. Prognostic models of 30-day mortality and morbidity after major pulmonary resection. J Thorac Cardiovasc Surg. 1999;117:969-79.

18. Birkmeyer JD, Siewers AE, Finlayson EV, Stukel TA, Lucas FL, Batista I, et al. Hospital volume and surgical mortality in the United States. N Engl J Med. 2002; 346:1128-37.

19. Gooiker GA, van Gijn W, Post PN, van de Velde CJ, Tollenaar RA, Klomp HM, et al. The relationship between volume or surgeon specialty and outcome in the surgical treatment of lung cancer: a systematic review and meta-analysis. $J$ Thorac Oncol. 2012;7:1170-8.

20. Boffa DJ, Allen MS, Grab JD, Gaissert HA, Harpole DH, Wright CD. Data from The Society of Thoracic Surgeons General Thoracic Surgery database: the surgical management of primary lung tumors. J Thorac Cardiovasc Surg. 2008;135:247-54.

21. Goodney PP, Lucas FL, Stukel TA, Birkmeyer JD. Surgeon specialty and operative mortality with lung resection. Ann Surg. 2005;241:179-84.

22. Iezzoni L. Risk Adjustment for Measuring Health Care Outcomes. 3rd ed. Chicago: Health Administration Press; 2003.

23. Quan H, Sundararajan V, Halfon P, Fong A, Burnand B, Luthi JC, et al. Coding algorithms for defining comorbidities in ICD-9-CM and ICD-10 administrative data. Med Care. 2005;43:1130-9.

24. Diggle PJ, Heagerty P, Liang KY, Zeger SL. Parametric models for covariance structure. In: Atkinson AC, Copas JB, Pierce DA, Schervish MJ, Titterington DM, Carroll RJ, eds. Analysis of Longitudinal Data. New York: Oxford University Press; 2002:81-113.

25. Van Schil PE, Balduyck B, De Waele M, Hendriks JM, Hertoghs M, Lauwers P. Surgical treatment of early-stage non-small-cell lung cancer. Eur J Cancer. 2013; 11:110-22.

26. Halm EA, Lee C, Chassin MR. Is volume related to outcome in health care? A systematic review and methodologic critique of the literature. Ann Intern Med. 2002;137:511-20.

27. Finley CJ, Bendzsak A, Tomlinson G, Keshavjee S, Urbach DR, Darling GE. The effect of regionalization on outcome in pulmonary lobectomy: a Canadian national study. J Thorac Cardiovasc Surg. 2010;140:757-63.

28. Handy JR Jr. Attributes contributing to superior outcomes in the surgical management of early-stage lung cancer and examples of implementing improvement. Cancer J. 2011;17:57-62.

29. Birkmeyer JD, Stukel TA, Siewers AE, Goodney PP, Wennberg DE, Lucas FL. Surgeon volume and operative mortality in the United States. $N$ Engl J Med. 2003;349:2117-27.

30. Li B, Evans D, Faris P, Dean S, Quan H. Risk adjustment performance of Charlson and Elixhauser comorbidities in ICD-9 and ICD-10 administrative databases. BMC Health Serv Res. 2008;8:12.

31. Needham D, Scales D, Laupacis A, Pronovost P. A systematic review of the Charlson Comorbidity Index using Canadian administrative databases: a perspective on risk adjustment in critical care research. J Crit Care. 2005;20:12-9.

32. Zhan C, Miller M. Administrative data based patient safety research: a critical review. Qual Saf Health Care. 2003;12:58-63.

33. Schneeweiss S, Maclure M. Use of comorbidity scores for control of confounding in studies using administrative databases. Int J Epidemiol. 2000;29:891-8.
Key Words: lung cancer, surgeon volume, resection, population

\section{Discussion}

Dr B. Stiles (New York, NY). We all have seen lots of studies about the morbidity and mortality with these operations, but we have seen few studies that govern the choice of operation and how that may affect overall mortality for the disease, so I do commend you on coming up with this idea and taking a look at it.

I have several questions. The first is related to pneumonectomy over time. Why do you think that it decreased over time? Was it better staging or do you think it is surgical learning or different surgeons coming in? That kind of sets up the context of the whole thing, being able to say we can decrease the need for pneumonectomy. It has decreased on its own over time, and I am curious to see why you think that is.

Dr Finley. The trend that we saw of physician experience held up over the time of the study. There are a number of factors that likely influenced the pneumonectomy rate: There is the regionalization that occurred in Canada at the time, positron emission tomography scans became widely available, and subsequently we had better staging for those large central tumors. Also, there are better skill sets. People in this day and age are better trained in transplant or vascular components of thoracic surgery, and the big vessels. Although it's impossible to know for certain.

Dr Stiles. You and I talked a bit about the next question. How do you define a high-volume surgeon? Particularly in this dataset, it may be a little challenging just picking a number in 1 year. The first-year surgeon who is performing 100 cases in this model gets labeled as being more experienced than one who has performed 30 lobectomies a year for 20 years. What are your thoughts on that and your definition of high volume?

Dr Finley. Ideally, you would like to know the level of training, how many years they have been in practice. It's just a limitation of the dataset that protects the anonymity of the institutions and the surgeons. We know it over 8 years, and so the best variable we could find was the yearly procedural volume. We clustered it so that an individual surgeon actually moved forward in time. It was all bundled together. You weren't judged on a single year but all of the years together as experience. You are right, it is a limitation.

Dr Stiles. What about alternatives to pneumonectomy, sometimes it's bilobectomy or sleeve lobectomy. How many of those were in the database and did you see many of those as the pneumonectomy rate decreased?

Dr Finley. You are right. It's infrequent. We tended to include all the lobectomies together because I feared that with an administrative dataset, the coding for those subtleties of procedure may be lost, and to presume that they were right may artificially influence the dataset, and so we tried to 
be inclusive. But you are right, ideally you would sort of see those more direct alternatives.

Dr Stiles. That is a great point. For me, the big issue is staging. I think the question is, in the smaller, low-volume places, are the patients just showing up later with bigger tumors? You showed some good data there at the end, showing that there is no relationship between stage and surgical volume. But the question for me is, is there a relationship between stage and the need for pneumonectomy in those last 2 years? Do you think better staging is sort of why the pneumonectomy rate decreased over time? Is that not part of what we are seeing here with the different surgeons?

Dr Finley. That is a good point too. The chance of receiving a pneumonectomy in stage I was small, in the $1 \%$ to $2 \%$ range. When you got to stages II and III, it was stable at approximately $15 \%$ to $16 \%$, and it seemed to be steady. So there wasn't really an influence of stage on procedure selection beyond what you would see typically between stage I and stages II and III.

Dr Stiles. I had the privilege of seeing it in the article, but I was hoping you could address the idea of wedge resections. Some of us would expect that surgeons with low volume are just going to do a wedge and sort of back out of a more difficult lobe. If you could just address that, I think this is an important issue too.

Dr Finley. It's true. Actually, your chance of doing a wedge resection goes down with procedural volume as well, by approximately $4 \%$ for every 10 that you do. So you have a less likely chance of performing a wedge and a less likely chance of performing a pneumonectomy as you gain more experience.

Dr Y. Colson (Boston, Mass). Do you have any way of tracking what the chemo-rads are? Are they tending to do more chemo-rads and less pneumonectomies? Do you think there is a change in how they are treating that group?

Dr Finley. At least the resection rate for all NSCLCs in Ontario has stayed stable at $18 \%$ for the last 15 years, and so it doesn't appear that there has been a migration that way, although I think there has been a balance, and the stages are presenting a bit earlier, but there is an increased number of patients being seen. It has stayed relatively steady. When we look across the country, there are certainly variations in access to care, and thus resection rates, and we are trying to drill down on if that influences people's survival and their options to get chemoradiotherapy, surgery, and other options.

Dr H. J. Hansen (Copenhagen, Denmark). Coming from Europe, I am not familiar with the Canadian system, but we have a great discussion right now about specialization. Some are cardiothoracic surgeons, some are pure thoracic, some are vascular thoracic, and some general surgeons perform thoracic surgery. Of course, you can emphasize that the surgeons with high volume are pure thoracic surgeons and the others might be general surgeons or whatever. Have you looked into the specialty of the single surgeon and should that have an effect, if it is a dedicated thoracic surgeon or another surgeon performing thoracic surgery now and then?

Dr Finley. I think you are right. Specific to specialty, it is in there, but it is probably not reliably coded enough to use it as a distinguishing factor. It wasn't included in the analysis because it is based on the hospital's designation of the practitioner, and so we thought it wasn't necessarily a fair representation. Canada has a robust system of training in that you have to do a thoracic 2-year fellowship and be Royal College certified. You are right. I do think other research has reliably shown that the level of training of a practitioner and the designation of the center and a number of other factors go into how good they are at delivering that care. I think there needs to be standards, to be perfectly honest. When I saw the presentation for esophageal cancer earlier today, all I could think of was that there needs to be accreditation or standards for the delivery of high-risk cancer surgery. It's inadvisable to let people do whatever they want. To perform 3 esophagectomies a year, I wouldn't let my mother have that operation in that place. It's just not acceptable to me. I think we all work in the climate that we work in, and we try our best to help patients as best we can.

Dr Y. Colson (Boston, Mass). If your theory, or at least your data, argues that it's not that we have just educated people over time, but that surgeon volume is important, then you should be able to look at your high-volume surgeons in 2004, and you should see that they have a different mix and were performing fewer pneumonectomies than others in 2004. Have you looked at what your high-volume surgeons in 2004 were doing?

Dr Finley. Do you mean if an individual surgeon migrated down over time, if I was practicing in 2004 and I did $20 \%$ and I migrated down to $10 \%$ over time? Yes, there is both an effect of time and of surgeon volume. So even a high-volume surgeon in 2004 would have performed more pneumonectomies than he/she would have done in 2011.

Dr T. Waddell (Toronto, Ontario, Canada). Did you look at hospital volume?

Dr Finley. Yes. It was removed from the multivariate model.

Dr Waddell. Because there is overlap between those 2 variables?

Dr Finley. It's strongly collinear with surgeon volume, and so we tried including interaction variables in a number of other ways, but whenever we used a multivariate model, it was the surgeon not the institution that drove the procedure selection, unlike mortality, which tends to be driven by institution. We have also performed other studies looking at complication rates and failure to rescue in thoracic and esophageal cancer and have found different relationships there, but in terms of what you choose to do, it tends to be more on you than on the institution. So even in an institution with a high volume, concentrating the experience in an individual's hands seems to be beneficial. 